\section{Informação Em Cultura}

v. 1, n. 2

jul./dez. 2019

ISSN: 2674-6549

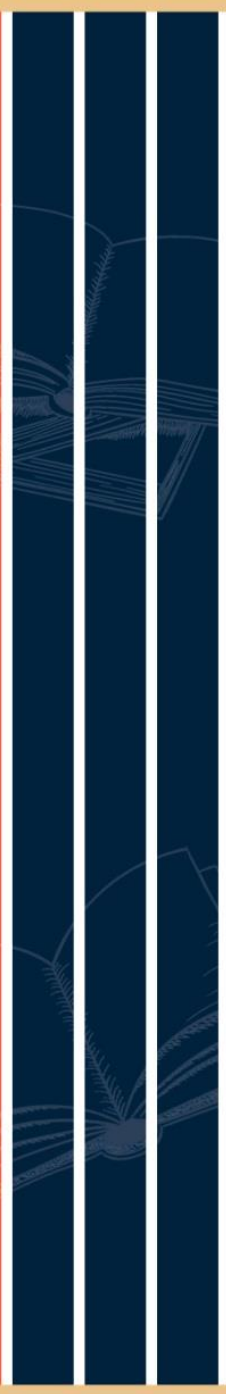

Submissão: 26/04/2019 Aprovação: 21/08/2019

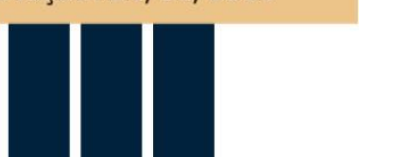

\title{
O PROCESSO DE RESSOCIALIZAÇÃO DE EGRESSOS DO SISTEMA PENITENCIÁRIO DA COMARCA DE CASCAVEL VIA PATRONATO: APONTAMENTOS SOBRE O PAPEL DO PEDAGOGO
}

THE PROCESS OF RESOCIALIZATION OF EGRESS FROM THE PENITENTIARY SYSTEM THROUGH PATRONATO: NOTES ON THE FUNCTION OF PEDAGOGY

\author{
Thaluan Rafael Debarba Baumbach ${ }^{1}$ \\ Marcio Issler ${ }^{2}$ \\ Valdecir Soligo ${ }^{3}$
}

\begin{abstract}
RESUMO
O presente artigo tem por objetivo estabelecer qual o papel do Pedagogo na perspectiva de Ressocialização de Egressos do Sistema Penitenciário da Comarca de Cascavel assistidos pelo Projeto Patronato UNIOESTE - Cascavel. Para tal, esta pesquisa conta com diferentes momentos, sendo elas: pesquisa bibliográfica e documental. No que se refere à pesquisa bibliográfica, os autores que fundamentam o desenvolvimento deste artigo são: Durkheim (1978), Machado (2008), Simões (2014), entre outros. Na abordagem documental, utilizamos a Lei de Execuções Penais - LEP do ano de 1984, a Lei de Drogas de 2006, o Código de Trânsito Brasileiro - CTB do ano de 1997, a Lei de Crimes Ambientais do ano de 2008, além de decretos municipais e editais institucionais referentes à Universidade que administra o Projeto. Como resultados, seguindo os objetivos propostos, apresentamos a perspectiva de ressocialização pautada na Lei de Execuções Penais, tendo o trabalho como atividade norteadora no processo de ressocialização dos assistidos pelo Projeto e o papel do Pedagogo. Concluímos que o profissional Pedagogo fora do ambiente escolar pode proporcionar atividades pouco conhecidas pelo senso comum, mas que constituem grande importância social.

Palavras-chave: Ressocialização. Projeto Patronato. UNIOESTE. Cidade de Cascavel/PR. Pedagogia não-escolar.
\end{abstract}

\section{ABSTRACT}

This article aims to establish the role of the Pedagogue in the perspective of the resocialization of graduates of the Cascavel County Penitentiary System, assisted by the UNIOESTE - Cascavel Patronate Project. For this, this research has different moments,

${ }^{1}$ Mestrando em Educação pela Universidade Estadual do Oeste do Paraná (UNIOESTE). Graduado em Pedagogia pela Universidade Estadual do Oeste do Paraná (UNIOESTE). Bolsista de Extensão pela Universidade Estadual do Oeste do Paraná (UNIOESTE). Lattes:

http://lattes.cnpq.br/7234688010577923. E-mail: thaluanunioeste@gmail.com.

${ }^{2}$ Mestre em Educação pela Universidade Estadual do Oeste do Paraná (UNIOESTE). Graduação em Pedagogia (UNIOESTE). Bolsista de Pesquisa pela Universidade Estadual do Oeste do Paraná (UNIOESTE). Lattes: http://lattes.cnpq.br/4825098013299442. E-mail: marcioissler@hotmail.com. ${ }^{3}$ Doutor em Educação pela Universidade do Vale do Rio dos Sinos (UNISINOS). Graduado em Pedagogia pela Universidade Paulista (UNIP). Professor da Universidade Estadual do Oeste do Paraná (UNIOESTE). Lattes: http://lattes.cnpq.br/5365966751665341. E-mail:

valdecir soligo@yahoo.com.br.

R. Inf. Cult., Mossoró, v.1, n.2, p. 69-92, jul./dez. 2019. E-ISSN: 2674-6549 
which are: bibliographic and documentary research. With regard to bibliographic research, the authors who support the development of this article are: Durkheim (1978); Machado (2008); Simões (2014), among others; In the documental approach we use the Law of Criminal Executions - LEP of 1984; the 2006 Drug Law; the Brazilian Traffic Code CTB of 1997; the Environmental Crimes Law of 2008; in addition to municipal decrees and institutional notices referring to the University that manages the Project. As results, following the proposed objectives, we present the perspective of resocialization based on the Law of Criminal Executions with work as a guiding activity in the process of resocialization of assisted by the Project and the role of the Pedagogue. We conclude that the professional Pedagogue outside the school environment can provide activities little known by common sense, but which are of great social importance.

Keywords: Resocialization. Employer Project. UNIOESTE. City of Cascavel / PR. Nonschool pedagogy.

\section{INTRODUÇÃO}

O presente texto visa apresentar o processo de ressocialização de egressos do sistema penitenciário da comarca de Cascavel via Patronato, proporcionando algumas reflexões acerca do papel do Pedagogo. Trata-se de um tema atual, que está presente no cotidiano de nossa sociedade. Segundo o Instituto Brasileiro de Geografia e Estatística (IBGE), em seu último censo populacional de 2010, a cidade de Cascavel contava com uma população de 286.205 pessoas, cuja estimativa para 2017 é de 319.608 pessoas, contando com um número de 208.621 votantes. Se considerarmos os dados midiáticos referentes ao mês de novembro de 2017, divulgados por meio do Jornal O Paraná (2017, online) ,a cidade contava com “[...] 1.313 presos, sendo 474 na PIC (Penitenciária Industrial de Cascavel); 766 na PEC (Penitenciária Estadual de Cascavel) e outros 73 na carceragem da 15a SDP (Subdivisão Policial)". No que diz respeito a 15a SDP, conforme Simões: "A capacidade da cadeia pública de Cascavel, localizada na 15으 subdivisão policial, é para 132 reclusos" (SIMÕES, 2014, p.3).

Nesses termos, a população carcerária no município de Cascavel não chega a compor $1 \%$ em relação ao público votante do mesmo período. Embora, se considerarmos essa população apenas como números, possivelmente, ignoraremos que estes, ao cumprirem sua pena, estarão novamente em meio à sociedade e carentes de políticas de ressocialização. Dados cedidos por meio do Patronato Penitenciário de Cascavel nos mostram que no mês de abril de 2018 a Comarca de 
Cascavel assistia 1.135 egressos de seu sistema penitenciário, beneficiados pela progressão de regime. Isso reflete a realidade presente nos presídios e fora deles. De fato, as unidades penais sobrevivem com recursos escassos, sejam eles materiais e/ou humanos.

Sabe-se que em todo o país que as unidades penais sofrem devido à falta de manutenção e a superlotação. Para além do número de presos em relação ao número de vagas disponíveis nas unidades penais, o sistema carcerário sofre de diversos outros problemas estruturais, como a falta de profissionais para o desenvolvimento das atividades. Estudos midiáticos recentes demonstram que nenhum Estado brasileiro se encontra de acordo com o número de agentes penitenciários ideais para o desenvolvimento dos presídios, sendo 5 presos para cada agente. Segundo informações obtidas no site do G1 (2018, online), no Estado do Paraná, encontram-se reclusos 30.000 pessoas e o número de Agentes Penitenciários é de 4.289, configurando, assim, cerca de 7 presos para cada agente. Isso decorre em insegurança dos Agentes no desenvolvimento de suas atividades, bem como, acarreta sérios problemas institucionais.

Figura 1 - Proporção preso por agente

\section{Paraná \\ Presos por agente:

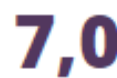 \\ Número de presos: Número de 30.000 agentes: 4.289}

Fonte: G1 (2018).

Assim sendo, esta pesquisa conta com diferentes momentos, sendo desenvolvida por meio de pesquisa bibliográfica e análises documentais. A temática abordada é a do processo de ressocialização de egressos do sistema penitenciário brasileiro, para tanto, alguns autores serão utilizados para abordar o tema que envolve a compreensão de sociedade, a ressocialização e a educação, entre eles: Durkheim (1978), tratando do conceito de sociedade, concepção de homem e o papel da 
educação no processo de ressocialização de egressos do sistema penitenciário; Machado (2008), com sua abordagem acerca da ressocialização sob orientações da Lei de Execuções Penais; Simões (2014), no que tange aos seus estudos referentes ao sistema carcerário na cidade de Cascavel; No que diz respeito à pesquisa documental, foram utilizadas as legislações que regem a Execução Penal no Brasil, entre elas: utilizemos a Lei de Execuções Penais - LEP do ano de 1984; a Lei de Drogas de 2006; o Código de Trânsito Brasileiro - CTB do ano de 1997; a Lei de Crimes Ambientais do ano de 2008; além de decretos municipais e editais institucionais referentes à Universidade que administra o Projeto. No âmbito da pesquisa bibliográfica e documental, seguiremos as orientações de Lakatos e Marconi (2003).

Nesses termos, o caminho construído durante a pesquisa foi facilitado pelo fato de que, no período explorado, desenvolvemos atividades em parceria com o departamento pedagógico no projeto de extensão denominado: Projeto Patronato UNIOESTE. Com isso, tive acesso ao banco de dados dos Assistidos, bem como desenvolvi com a equipe do Departamento Penitenciário do Estado do Paraná - DEPEN a fiscalização dos egressos do sistema penitenciário. Ademais, boa parte da documentação analisada nesse texto está disponível para o público, por meio do site do DEPEN ou em artigos que trabalham a mesma temática. No que se refere ao papel do Pedagogo no Projeto, podemos vivenciar em parceria com o Departamento Pedagógico do Projeto a relação teoria e prática, elencando os itens contidos no Projeto e a realização das atividades.

Nesse contexto, buscaremos apresentar as características do município de Cascavel, sobretudo no que se refere ao contexto histórico de desenvolvimento e aplicação de políticas públicas de ressocialização de egressos do sistema prisional. A partir disso, apresentaremos a compreensão de Homem, Sociedade e Estado contidos em Durkheim (1978), a fim de relacionar o papel da educação no processo de ressocialização. Por fim, apresentamos o papel do Pedagogo no processo de ressocialização presente no Patronato Penitenciário de Cascavel. 


\section{DE PRÓ-EGRESSO AO PATRONATO: DOIS PROGRAMAS UM OBJETIVO}

O Pró-Egresso, desenvolvido pelo Departamento Penitenciário do Estado do Paraná (DEPEN), é um projeto antecessor à criação do Patronato Penitenciário do Paraná. Inicialmente, o Pró-Egresso visava atender os egressos do sistema prisional em cada município de atuação. Após a visualização dos resultados, tal iniciativa teve ampliação e passou a atender os egressos das penitenciárias estaduais. No Estado do Paraná, o Programa Patronato teve início na cidade de Londrina, por meio dos esforços da Universidade Pública Estadual da mesma cidade. A partir desse momento, criou-se o vínculo entre o Departamento Penitenciário e a Universidade Estadual. Tal vínculo passou a se estabelecer nas outras comarcas do Estado, buscando atender à demanda da criação de metodologias de ressocialização.

O papel do Pró-Egresso era o de fiscalização, bem como o de estimular a inclusão de egressos no mercado de trabalho, porém a questão da ressocialização e de medidas para tal inclusão eram deficitárias, mas que seriam ampliadas com a realização da parceria com a Universidade, ainda nesse sentido:

Caracteriza-se como Unidade do DEPEN, que no Estado do Paraná coordena a execução dos Programas Pró-Egresso, em seu desenvolvimento, fornecendo supervisão e infraestrutura para os programas, visando ao cumprimento da Lei no 7.210/84, de Execuções Penais (DEPEN, 2018, p. 2).

Nesse sentido, o trabalho desenvolvido pelos Patronatos Penitenciários do Estado do Paraná, por meio de fiscalização e medidas de ressocialização, vem sendo acompanhado e apoiado pelo Ministério de Segurança Pública, pelas varas de execuções penais de suas referidas comarcas, enfatizando-se a execução da pena como um processo jurídico-social e de ressocialização.

Mais especificamente sobre o primeiro Patronato criado no Estado, ou seja, o de Londrina, é importante destacar a realização do "Programa Themis" e a influência da colônia penal no processo de realização de fiscalização das penas, sobretudo no regime semiaberto. O "Programa Themis" teve início no ano de 1985, a partir da lei 7.210/84, que passou a determinar a assistência ao apenado e egresso dos estabelecimentos penais. A partir desse programa, foi instituído o Programa Pró- 
egresso, que posteriormente se tornaria o Programa Patronato. Mas no que difere esses programas? Em tese, todos visam o mesmo objetivo, que seria a fiscalização da pena e a busca pela ressocialização de seus assistidos. De fato, o Programa Patronato vem a ser a terceira versão nesse processo, tendo como parceiro as universidades Públicas de sua Comarca.

Vale ressaltar o papel da colônia penal, como anteriormente mencionado, nesse processo de ressocialização. De acordo com os manuais do DEPEN, a colônia penal é um "Estabelecimento Penal de segurança média, destinado a presos do sexo masculino, em cumprimento da pena, gozando do benefício do regime semiaberto" (DEPEN, 2018a, p. 1). Ao progredir do regime fechado para o regime semiaberto, o detento passa a gozar dessa liberdade condicionada, sendo que, em sua audiência de progressão de regime, são impostas algumas condições para permanecer em tal regime, que, se não forem cumpridas, incorre na regressão de regime, podendo retornar para o regime fechado. Na comarca de Cascavel não existe uma colônia penal, portanto não havendo distinção entre o regime semiaberto e o regime aberto.

A Lei de Execuções Penais Brasileiras (LEP) regimenta o cumprimento das penas em todo território nacional, além dela, temos as Leis de Drogas 11.343/06, de Crimes Ambientais 9.605/08 e o Código Brasileiro de Trânsito (СTB) 9.503/97. No que diz respeito à LEP, em seu artigo primeiro, temos sua definição:

Art. 10 A execução penal tem por objetivo efetivar as disposições de sentença ou decisão criminal e proporcionar condições para a harmônica integração social do condenado e do internado (BRASIL, 1984).

Nesse sentido, o Patronato Penitenciário é um órgão de execução penal, que de acordo com a Lei de execuções penais 7.210/84, em seu artigo 78 e 79, estabelece suas determinações:

Art. 78. O Patronato público ou particular destina-se a prestar assistência aos albergados e aos egressos (artigo 26). Art. 79. Incumbe também ao Patronato: I - orientar os condenados à pena restritiva de direitos; II fiscalizar o cumprimento das penas de prestação de serviço à comunidade e de limitação de fim de semana; III - colaborar na fiscalização do cumprimento das condições da suspensão e do livramento condicional (BRASIL, 1984). 
Ainda nessa Lei, no que se refere ao livramento condicional, cabe ao Patronato, como determina o artigo 139:

\begin{abstract}
Art. 139. A observação cautelar e a proteção realizadas por serviço social penitenciário, Patronato ou Conselho da Comunidade terão a finalidade de: I - fazer observar o cumprimento das condições especificadas na sentença concessiva do benefício; II - proteger o beneficiário, orientando-o na execução de suas obrigações e auxiliando-o na obtenção de atividade laborativa. Parágrafo único. A entidade encarregada da observação cautelar e da proteção do liberado apresentará relatório ao Conselho Penitenciário, para efeito da representação prevista nos artigos 143 e 144 desta Lei (BRASIL, 1984).
\end{abstract}

Como podemos visualizar, o Patronato está diretamente regido pela lei de Execuções Penais Brasileiras. Nesse processo, na cidade de Cascavel - Paraná, no ano de 2010, ocorreu a mudança de Pró-egresso para Patronato. De acordo com o Decreto Estadual no 8839, fica estabelecida a criação do Patronato como órgão de Execução penal desta comarca:

Art. 10 Ficam criadas na estrutura organizacional do Departamento Penitenciário do Estado do Paraná - DEPEN, unidade de execução programática da secretaria do Estado da Justiça e da Cidadania - SEJU, os seguintes estabelecimentos penais: I - Patronato Penitenciário de Cascavel; e II - Penitenciária Estadual de Cruzeiro do Oeste (PCO) (PARANÁ, 2010, p.3-4).

Desde então foi estabelecido um diálogo entre o DEPEN e a Universidade Estadual do Oeste do Paraná (UNIOESTE) em prol de viabilizar a realização de subprojetos cujo intuito fosse a qualificação de mão de obra dos egressos do sistema prisional e acompanhamento multidisciplinar visando a ressocialização desses assistidos $^{4}$. Tal diálogo percorreu algumas intempéries, levando a se estabelecer apenas no ano de 2018, quando foi instrumentalizado por uma equipe multidisciplinar, contando com um profissional de cada área estabelecida pelo Edital $n^{\circ}$ 01/2018 Programa Patronato Cascavel UNIOESTE, sendo elas: Assistência Social, Direito, Pedagogia e Psicologia. O Programa anteriormente citado está vinculado ao Programa de Extensão Universidade Sem Fronteiras - SETI/USF e ao Subprograma: incubadora

${ }^{4} \mathrm{O}$ termo "assistido" que será referenciado em diversos momentos no decorrer deste texto visa desmistificar preconceitos com os egressos do Sistema Penitenciário Estadual, bem como, estabelece uma relação de assistencialismo. 
dos Direitos Sociais - PATRONATO, em conjunto com a direção de Campus da UNIOESTE - Campus de Cascavel (UNIOESTE, 2018).

De modo a suprir as demandas organizacionais e de espaço físico para a realização das atividades administrativas e de atendimento multidisciplinar, foi realizado um convênio com a Prefeitura Municipal de Cascavel a fim de estabelecer a permissão de uso de bem imóvel. Desse modo, por meio do Decreto Municipal no 13.532, foi autorizada a utilização de duas salas situadas no piso superior da rodoviária da cidade de Cascavel:

Art. 10 Fica autorizada a permissão de uso de 02 (duas) salas localizadas no andar superior do Terminal Rodoviário de Cascavel, sob nos $229 \mathrm{C}$ e $230 \mathrm{C}$ situadas na Avenida Assunção 1757, Centro - CEP 85805-030, desta cidade de Cascavel - PR para uso do Patronato Penitenciário do Estado do Paraná (CASCAVEL, 2017, p.1).

Nesses termos, o Programa Patronato Cascavel - UNIOESTE, em sede própria, visa prestar assistência social, jurídica, pedagógica e psicológica aos egressos do Sistema Penitenciário residentes na comarca de Cascavel - Paraná. Entre eles, encontram-se cidadãos que foram beneficiados com a progressão de regime, podendo estar no regime semiaberto com monitorização eletrônica, no regime semiaberto harmonizado (quando não há monitorização eletrônica) e no regime aberto. Além das situações de progressão de regime, são assistidos pelo Patronato aqueles que foram determinados judicialmente a cumprimento de Prestação de Serviços à Comunidade (PSC) por determinação da Vara de Execuções Penais e dos Juízes das Varas Criminais.

Desta forma, o Projeto Patronato Cascavel - UNIOESTE promove juntamente aos assistidos apoio no cumprimento da determinação judicial. Nessa perspectiva, o intuito das atividades se destaca pela busca da reinserção social, contando com a participação nos grupos de reflexão, cursos profissionalizantes, encaminhamento para tratamentos e estudos, proporcionando um ganho para o assistido e uma oportunidade de mudança de vida, bem como contribuindo com o desenvolvimento da sociedade e diminuindo a reincidência criminal.

Para tal, serão apresentados alguns parâmetros da realização dos trabalhos desenvolvidos pelas áreas interdisciplinares, com ênfase no trabalho desenvolvido 
pelo profissional Pedagogo. Segundo as diretrizes estabelecidas pela equipe de profissionais do Patronato, o eixo norteador proporciona: Fomentar e organizar cursos de formação, capacitação ou aperfeiçoamento profissionais, tendo como eixo uma política penitenciária que, efetivamente, almeja a reintegração social do preso; Sistematizar e produzir procedimentos padrões para as áreas; Elaborar diretrizes para desencadear um processo de avaliação institucional e de pessoal em todas as esferas envolvidas com gestão no âmbito do Patronato Penitenciário de Cascavel; Executar pesquisas científicas, com o objetivo de se obter dados científicos que, por um lado, forneçam um diagnóstico da realidade dos egressos e, por outro, apontem os caminhos a serem trilhados. Acompanhar e articular a escrita e desenvolvimento dos projetos, sem interferir no que se refere à especificidade de cada área.

No que diz respeito à área do Serviço Social, busca-se a promoção da condição social dos assistidos(as) do Projeto Patronato de Cascavel-PR, bem como desenvolvimento de possibilidades que contribuam para a ressocialização dos egressos e a diminuição do índice de reincidência criminal. Nesses termos, os profissionais da área buscam: Realizar atendimento aos assistidos no que se refere à matéria de Serviço Social, sustentado na dimensão teórico-metodológica, técnico-operativa e ético política; Acompanhar o assistido do início ao fim do cumprimento de sua pena, identificando possibilidades de inclusão em atividades que promoverão sua reinserção social; Acompanhar os beneficiados com penas restritivas de direito: os Prestadores de Serviços à Comunidade (PSC) em entidades conveniadas, como hospitais públicos; Atender as famílias dos assistidos, com projetos específicos, bem como com encaminhamentos para as diferentes políticas setoriais, quando houver necessidade.

No que diz respeito à atividade desenvolvida pelo departamento psicológico do Patronato, é importante citar a realização de entrevistas iniciais, nas quais é almejado identificar possíveis demandas psicológicas a serem acompanhadas. Em continuidade ao atendimento, o setor desenvolve o acompanhamento dos assistidos que, porventura, demonstrarem interesse e/ou for identificada a necessidade pelo profissional da área. Ainda em tempo, o setor realiza atividades de conscientização e ressocialização com os assistidos que tiveram sua condenação no artigo 33 da lei de drogas (tráfico de drogas). Vale ressaltar a demanda nos atendimentos e que não cabe 
ao setor realizar atendimentos clínicos, sendo apenas realizado atendimento inicial, acompanhamento e encaminhamentos, quando necessário.

Por fim, porém não menos importante, temos o setor jurídico que é responsável por toda a parte judicial desse órgão de execução penal. A esse setor cabe: viabilizar o contato mediante sistema PROJUDI ${ }^{5}$ com os juízes e promotores das Varas de Execuções Penais dessa comarca; proporcionar esclarecimentos do campo jurídico aos assistidos. Além de todo aporte interno, o departamento jurídico desenvolve ações em parceria com as Penitenciarias da comarca, e entidades parceiras desenvolvendo atividades e subprojetos que visam a ressocialização dos assistidos.

\section{EDUCAÇÃO: RESSOCIALIZAÇÃO E SOCIEDADE}

De modo a estabelecer alguns parâmetros iniciais, devemos considerar a compreensão que norteará nossa interpretação acerca do papel da Educação no processo de ressocialização. Assim dizendo, os conceitos de Estado, sociedade e até mesmo de homem necessitam estar explicitados. Nesses termos, no que se refere à interpretação de Sociedade e Estado, utilizaremos o embasamento de alguns autores, entre eles, temos Émile Durkheim (1858 - 1917). A visão de Durkheim, no que diz respeito à sociedade, relata da busca de uma harmonia social sendo que qualquer alteração ocorrente pode ser tratada com coerção das forças sociais, a fim de retornar a Harmonia. Nesses termos, ele estabelece para cada indivíduo um determinado papel social que deve ser cumprido, por meio da divisão social do trabalho. Brevemente falando, o Estado fica evidenciado nas obras do autor, como uma instituição responsável por manter a divisão social do trabalho, sendo capaz de garantir essa realidade social.

${ }^{5}$ O PROJUDI é um programa de computador que pode ser utilizado através da Internet e permite a completa substituição do papel por autos processuais digitais. O funcionamento do PROJUDI é bastante simples e seguro. Os advogados e os cidadãos que desejem ingressar com alguma reclamação nos Juizados Especiais podem utilizar a Internet ou se dirigir ao setor de atendimento dos juizados. Esses pedidos serão registrados eletronicamente, com distribuição e cadastramento automático do processo. A partir daí todos os atos serão realizados utilizando-se o computador, com a eliminação do papel. 
No que diz respeito à educação, ela: “[...] não é, pois, para a sociedade, senão o meio pelo qual ela prepara, no íntimo das crianças, as condições essenciais da própria existência" (DURKHEIM, 1978, p. 41). Ainda em tempo, a educação é uma ação exercida com o objetivo de desenvolver estados físicos, intelectuais e morais estipulados pela sociedade política, em conjunto ao meio que a criança se insere. Desse modo, estabelecendo como finalidade a expressão social à qual fazemos parte, destacando as: "[...] crenças religiosas, as crenças e as práticas morais, as tradições nacionais ou profissionais, as opiniões coletivas de toda espécie. Seu conjunto forma o ser social" (DURKHEIM, 1978, p. 42). Nesse sentido, o autor estabelece a importância da ação educativa, pois constitui os estados mentais a partir de uma visão sociológica. Assim, o autor destaca a existência de dois seres indissociáveis que são distintos:

\begin{abstract}
Um é constituído de todos os estados mentais que não se relacionam senão conosco mesmo e com os acontecimentos de nossa vida pessoal: é o que se poderia chamar de ser individual. O outro é um sistema de ideias, sentimentos e de hábitos que exprimem em nós, não a nossa individualidade, mas o grupo ou os grupos diferentes de que fazemos parte; tais são as crenças religiosas, as crenças e as práticas morais, as tradições nacionais ou profissionais, as opiniões coletivas de toda a espécie. Seu conjunto forma o ser social. Constituir este ser em cada um de nós - tal é o fim da educação (DURKHEIM, 1978, p. 82-83, grifos do autor).
\end{abstract}

Evidenciando a concepção de sociedade presente em Durkheim (1978), podemos perceber que o Patronato Penitenciário de Cascavel possui características de um órgão que busca a harmonia social. Ao estabelecer medidas de Políticas Públicas com vistas à ressocialização com os egressos do sistema prisional, o Patronato se configura como uma entidade de assistência social, que busca integrar o individual ao grupo social, devolvendo-lhes as condições mínimas de vida em sociedade.

Nesse contexto, ao visualizarmos o conjunto de leis que regem a vida dos apenados em sociedade, temos o sistema de progressão de regime, que foi estabelecido no Brasil a partir da década de 1940. Desde então, algumas alterações metodológicas foram estabelecidas. Ademais, a Lei de Execução Penal é bem clara no que diz respeito a sua finalidade, sendo ela a busca pela ressocialização dos indivíduos em conflito com a Lei, no entanto, nem todos os estabelecimentos penais brasileiros contam com a estrutura mínima para proporcionar tais medidas de ressocialização, conforme Machado (2008, p.48): 
Não há dúvida sobre a necessidade de se respeitar os direitos dos reclusos embora muitos adeptos ao radicalismo defendam que a legislação carcerária brasileira é protecionista, é notório que a vida nos presídios, na maioria das vezes, não respeita os mínimos indícios do direito fundamental da dignidade da pessoa humana.

Nesses termos, devemos considerar que os apenados que são assistidos pelo projeto Patronato podem ser considerados como indivíduos com suas potencialidades a serem trabalhadas, visando a superação de suas dificuldades a fim de diminuir os índices de reincidência no crime, bem como sendo capaz de possibilitar a tão almejada reintegração social.

Considerando que o primeiro estágio do cumprimento de pena ocorre em regime fechado, é correto afirmar que nele inicia o processo de ressocialização, e sua continuidade nos regimes semiaberto e aberto, além de fazer parte da legislação, é de suma importância para a diminuição dos índices de ressocialização. A Educação desenvolvida dentro dos presídios, bem como a desenvolvida fora deles visa a ressocialização. Para que haja a ressocialização, propriamente dita, não basta que seja cumprido apenas o que é expresso nos mandados de fiscalização dos egressos do sistema carcerário. Entre as condições mínimas contidas na progressão de regime constam: possuir residência fixa; seja exercido trabalho honesto; não se ausentar da comarca em prazo determinado; recolher-se em residência fixa no horário determinado; entre outras especificidades. No entanto, compreendemos que, para que ocorra a integração social desses egressos, seja necessário permitir condições humanizadoras que vão para além das expressas em seu mandado de fiscalização.

Ainda que a Lei de Execuções Penais brasileira seja considerada uma das mais avançadas do mundo, no que tange ao processo de ressocialização de pessoas em conflito com a lei, sendo possível o trabalho ainda no regime fechado, culminando em remissão de dias de pena (MACHADO, 2008), as indagações que pairam sobre o estudo desenvolvido é de: o que seria essa tal ressocialização? Compreende-se a ressocialização como modificar as ações dos presos e egressos do sistema prisional, para que estes sejam adequados ao que é socialmente aceito. No entanto, seria apenas isso? 


\section{A RESSOCIALIZAÇÃO DE EGRESSOS DO SISTEMA PRISIONAL SEGUNDO}

\section{A LEI DE EXECUÇÕES PENAIS}

A Lei de Execuções Penais é muito clara quanto aos deveres do Estado, no que tange à assistência mínima a ser desprendida aos presos em sua custódia. Logo em seu segundo capítulo apresenta tais disposições (BRASIL, 1984):

Art. 10. A assistência ao preso e ao internado é dever do Estado, objetivando prevenir o crime e orientar o retorno à convivência em sociedade. Parágrafo único. A assistência estende-se ao egresso. Art. 11. A assistência será: I - material; II - à saúde; III - jurídica; IV - educacional; V social; VI - religiosa.

No que diz respeito à assistência material, está previsto o fornecimento de alimentação, vestuário e instalações higiênicas (BRASIL, 1984). No que cabe ao atendimento à saúde, são destacados 3 atendimentos, sendo eles: médico, farmacêutico e odontológico (BRASIL, 1984). Acerca da assistência jurídica, fica destinado aos presos incapacitados de constituírem, por meios próprios, advogados dativos do Estado. Para o desenvolvimento educacional, é previsto pela LEP: “Art. 18. O ensino de 10 grau será obrigatório, integrando-se no sistema escolar da Unidade Federativa". Além disso, formação profissional, cuja finalidade é a profissionalização do apenado, o que o permitirá a continuidade nas condições socais mínimas, após o cumprimento do período em regime fechado que lhe foi imposto. Quanto à Assistência Social (BRASIL, 1984):

Art. 22. A assistência social tem por finalidade amparar o preso e o internado e prepará-los para o retorno à liberdade. Art. 23. Incumbe ao serviço de assistência social: I - conhecer os resultados dos diagnósticos ou exames; II - relatar, por escrito, ao Diretor do estabelecimento, os problemas e as dificuldades enfrentadas pelo assistido; III - acompanhar o resultado das permissões de saídas e das saídas temporárias; IV promover, no estabelecimento, pelos meios disponíveis, a recreação; $V$ promover a orientação do assistido, na fase final do cumprimento da pena, e do liberando, de modo a facilitar o seu retorno à liberdade; VI providenciar a obtenção de documentos, dos benefícios da Previdência Social e do seguro por acidente no trabalho; VII - orientar e amparar, quando necessário, a família do preso, do internado e da vítima. 
E no que diz respeito à assistência religiosa, é garantido na Lei no 7210/84 a liberdade do culto, possibilitando a posse de livros religiosos. Fica estabelecido também que as unidades penais deverão proporcionar espaços para a realização de cultos e não poderá obrigar nenhum preso a participar de tais atividades (BRASIL, 1984). Nesse contexto, e de acordo com diversos trabalhos do campo do direito, tratando da ressocialização de egressos sob a luz da execução penal, temos o trabalho (atividade laboral), como item basilar. Para subsidiar as discussões acerca do trabalho como elemento fundamental no processo de ressocialização desses assistidos, iremos nos apropriar dos artigos norteadores do Estatuto Penitenciário do Estado do Paraná:

Art.3ำ Os Estabelecimentos Presidiários destinam-se aos presos provisórios e aos sujeitos à prisão simples e à prisão especial. § 1ㅇ - Nas comarcas onde não existem Estabelecimentos Presidiários, suas finalidades serão, excepcionalmente, atribuídas às cadeias públicas locais, observadas as normas deste Estatuto, no que forem aplicáveis, e as restrições legais ou de decisões judiciais. § 2ㅇ - Ao preso provisório será assegurado regime especial no qual se observará: I. separação dos presos condenados; II. cela individual, preferencialmente; III. opção por alimentar-se às suas expensas; IV. utilização de pertences pessoais; V. uso de sua própria roupa ou, quando for o caso, de uniforme diferenciado daquele utilizado por preso condenado; VI. oferecimento de oportunidade de trabalho; VII. visita e atendimento do seu médico ou dentista (DEPEN, 1995).

Em seu artigo terceiro, o presente estatuto configura a perspectiva de como os presos devem ser condicionados ao estarem adentrando ao sistema prisional. Nesse aspecto inicial, fica evidenciado que no item VI é proporcionado ao interno a possibilidade de trabalho. O trabalho no sistema penitenciário cumpre um papel importe na reconstrução do caráter do indivíduo tendo sua reinserção social. Nesses termos é disposto no: “Art. 39 - É dever do condenado trabalhar durante o dia, na medida de suas aptidões e capacidade. Ao preso provisório o trabalho não é obrigatório" (DEPEN, 1995). A partir disso, tem-se a constituição de diferentes formas de trabalho, sendo eles distribuídos no ambiente interno do presídio e no ambiente externo. Para o ambiente externo temos como explicações o:

Art. 410 trabalho externo somente será autorizado quando o preso estiver em execução de pena. § 10 - Ao preso ou internado será garantido trabalho remunerado conforme sua aptidão e condição pessoal, respeitada a determinação médica. $\S 2$ 으 - Será proporcionado ao preso ou internado trabalho educativo e produtivo. $\S$ З으- Devem ser consideradas as 
necessidades futuras do preso ou internado, bem como as oportunidades oferecidas pelo mercado de trabalho (DEPEN, 1995).

Para proporcionar a continuidade dessa perspectiva de ressocialização, agora nos regimes semiaberto, aberto e liberdade condicional, são estabelecidas pelo Patronato Penitenciário metodologias de ações. Nesse processo, é função do Patronato, ao receber estes indivíduos em progressão de regime além de desenvolver sua fiscalização de pena realizar acompanhamentos pedagógicos, sócias, psicológicos e jurídicos. Nesses termos, cabe ao departamento pedagógico do Patronato desenvolver ações a fim de monitorar as atividades laborativas desses egressos, visando o melhor desenvolvimento de suas potencialidades. A fim de compreender as atribuições estipuladas pelo Estatuto em seu artigo 25 item $V$ fica exposto os objetivos que devem ser almejados no campo do trabalho.

V. promover a assistência ao condenado a que se refere o inciso anterior, objetivando a reeducação social e a reintegração à comunidade por meio de formação profissional, colocação empregatícia, habitação, transporte, saúde, educação, atendimento jurídico, psicológico, material e religioso, na forma do capítulo II da Lei Federal no. 7.210/87 (BRASIL, 1987).

Nessa perspectiva, evidencia-se que o trabalho (como atividade laborativa), assume papel de influência primordial e norteadora das ações de ressocialização dos assistidos do Patronato. Ainda que, em tratar-se de condição primordial para manterse na progressão de regime, boa parte dos assistidos enfrentem severas e duras dificuldades na busca por um trabalho direto, ou seja, de carteira assinada. A grande maioria sai do sistema penitenciário sem ao menos portar documentação básica, como cédula de R.G. (Registro Geral/Documento de Identificação/Identidade) e até mesmo Carteira de Trabalho. Nesse contexto, o departamento de Assistência Social proporciona o acompanhamento necessário a fim de providenciar a confecção desses documentos e o departamento pedagógico por meio de parcerias com entidades público e privadas visam constituir um emprego digno para os assistidos. No entanto, isso é conteúdo que será abordado na próxima sessão. 


\section{O PAPEL DO PEDAGOGO VIA PATRONATO NO PROCESSO DE RESSOCIALIZAÇÃO DOS EGRESSOS DO SISTEMA PENITENCIÁRIO DA COMARCA DE CASCAVEL}

De acordo com o senso comum, tem-se que o papel principal do Pedagogo seja

a docência e perpetua-se, nos cursos de formação de professores, uma visão norteadora para tal, porém existem outras possibilidades. A resolução 02/2015 define as D.C.N.'s (Diretrizes Curriculares Nacionais) para a formação inicial de professores em nível superior. E será a partir dessa resolução que pautaremos as discussões iniciais acerca da formação do Pedagogo, sobretudo no que tange a sua atuação no processo de ressocialização de egressos do sistema penitenciário. A referida resolução considera a realidade brasileira sobre a formação de professores e estabelece parâmetros básicos em currículos de formação de professores. Em seu artigo primeiro estabelece:

Art. 10 Ficam instituídas, por meio da presente Resolução, as Diretrizes Curriculares Nacionais para a Formação Inicial e Continuada em Nível Superior de Profissionais do Magistério para a Educação Básica, definindo princípios, fundamentos, dinâmica formativa e procedimentos a serem observados nas políticas, na gestão e nos 3 programas e cursos de formação, bem como no planejamento, nos processos de avaliação e de regulação das instituições de educação que as ofertam (BRASIL, 2015, p. 2 3).

Os esforços em estabelecer parâmetros mínimos para a formação de professores caracterizam-se como uma preocupação acerca da política de formação de professores em geral. Ao estabelecer as Diretrizes Curriculares Nacionais para formação de professores, ocorreu uma padronização dos cursos, buscando configurar uma unidade dos P.P.P. (Projetos Políticos Pedagógicos) em nível nacional. Nesse sentido, o terceiro artigo da referida diretriz estabelece as funções mínimas necessárias a compor o bojo da formação dos professores:

Art. 3o A formação inicial e a formação continuada destinam-se, respectivamente, à preparação e ao desenvolvimento de profissionais para funções de magistério na educação básica em suas etapas - educação infantil, ensino fundamental, ensino médio - e modalidades - educação de jovens e adultos, educação especial, educação profissional e técnica de nível médio, educação escolar indígena, educação do campo, educação escolar quilombola e educação a distância - a partir de compreensão ampla 
e contextualizada de educação e educação escolar, visando assegurar a produção e difusão de conhecimentos de determinada área e a participação na elaboração e implementação do projeto político-pedagógico da instituição, na perspectiva de garantir, com qualidade, os 4 direitos e objetivos de aprendizagem e o seu desenvolvimento, a gestão democrática e a avaliação institucional (BRASIL, 2015, p. 3 - 4).

Acerca da formação inicial e continuada de professores, a diretriz estabelece que deve compor como habilitação o ensino para educação básica em suas diversas etapas e modalidades, e isso implica na produção e difusão de conhecimentos científicos. Nesse sentido, deve haver uma compreensão ampla e contextualizada de educação, buscando a produção e difusão de conhecimentos científicos. Para a realização das atividades básicas, foram atribuídos requisitos mínimos a serem cumpridos pelos cursos superiores de Licenciatura. Em seu décimo terceiro artigo, a diretriz estabelece a quantidade de horas que devem estar presentes durante a formação inicial dos professores.

Art. 13. Os cursos de formação inicial de professores para a educação básica em nível superior, em cursos de licenciatura, organizados em áreas especializadas, por componente curricular ou por campo de conhecimento e/ou interdisciplinar, considerando-se a complexidade e multirreferencialidade dos estudos que os englobam, bem como a formação para o exercício integrado e indissociável da docência na educação básica, incluindo o ensino e a gestão educacional, e dos processos educativos escolares e não escolares, da produção e difusão do conhecimento científico, tecnológico e educacional, estruturam-se por meio da garantia de base comum nacional das orientações curriculares (BRASIL, 2015, p. 11, grifos nossos).

Torna-se de extrema importância para esta discussão a expressão presente no excerto retirado da diretriz de formação inicial de professores no que se refere aos processos educativos escolares e não escolares, esse contempla, entre outros aspectos, o papel do Pedagogo fora do ambiente escolar. Entretanto, a mesma diretriz, em seu parágrafo 5으, no que diz respeito especificamente ao curso de Pedagogia, estabelece uma tendência à formação inicial com ênfase ao ensino:

§ 5o Nas licenciaturas, curso de Pedagogia, em educação infantil e anos iniciais do ensino fundamental a serem desenvolvidas em projetos de cursos articulados, deverão preponderar os tempos dedicados à constituição de conhecimento sobre os objetos de ensino, e nas demais 
licenciaturas o tempo dedicado às dimensões pedagógicas não será inferior à quinta parte da carga horária total (BRASIL, 2015, p. 12).

Nesse contexto, apresenta-se inicialmente um perfil de profissional a ser formado por cursos de licenciatura no país, sobretudo no que diz respeito ao curso de Pedagogia. É importante ressaltar que antes do estabelecimento dessa diretriz, os cursos de formação de professores seguiam orientações distintas e, a partir delas, passaram a seguir uma unidade em sua formação.

A compreensão do profissional de educação, mais especificamente do Pedagogo fora do ambiente escolar, em diferentes situações, é tratada com certo desprezo nos cursos de formação inicial. De todo modo, os currículos do curso de Pedagogia, em todo território nacional, propiciam subsídios metodológicos e práticos para que o profissional atue dentro e fora do ambiente escolar.

Concursos públicos e instituições privadas, cada vez mais, necessitam desses profissionais para atuarem além do ambiente de sala de aula e do contexto escolar. Um exemplo disso é o departamento pedagógico presente em instituições prisionais vinculados ao DEPEN no Estado do Paraná, e mais especificamente ao Patronato Penitenciário, foco dessa pesquisa.

Desse modo, apresentaremos o plano de ação do profissional Pedagogo no ambiente do Patronato Penitenciário de Cascavel, visando assim estabelecer parâmetros iniciais para uma discussão acerca da importância desse profissional no processo de ressocialização de egressos. Nesse sentido, são objetivos destacados no plano de ação do departamento pedagógico:

(I) Favorecer a formação ampliando a capacitação dos profissionais a partir da socialização de experiências, dúvidas, medos e ideais. (II) Promover a condição social dos assistidos do Projeto Patronato de Cascavel-PR, bem como desenvolver possibilidades que contribuam para a ressocialização dos egressos e a diminuição (DEPEN, 2018c, p.7).

Ao estabelecer os parâmetros basais das ações do departamento pedagógico presente no Patronato Penitenciário de Cascavel, objetivou-se proporcionar uma dinâmica de trabalho voltada para reinserção do assistido no mercado de trabalho. Nessa direção, têm-se como estratégias de ação alguns princípios norteadores, entre eles: 
Fomentar e organizar cursos de formação, capacitação ou aperfeiçoamento profissionais, tendo como eixo uma política penitenciária que, efetivamente, apostasse na reintegração do preso na sociedade; Sistematizar e produzir procedimentos padrões para as áreas; Elaborar diretrizes para desencadear um processo de avaliação institucional e de pessoal em todas as esferas envolvidas com gestão no âmbito do Patronato Penitenciário de Cascavel; Executar pesquisas científicas, com o objetivo de se obter dados científicos que, por um lado, forneçam um diagnóstico da realidade dos egressos e, por outro, apontem os caminhos a serem trilhados. Acompanhar e articular a escrita e desenvolvimento dos projetos, sem interferir no que se refere a especificidade de cada área (DEPEN, 2018c, p.8).

Diante do exposto, a fim de aproximar o leitor das técnicas e metodologias utilizadas pelo profissional de educação Pedagogo no ambiente não escolar, o sistema penitenciário, serão apresentados os itens componentes desse processo. No que cerne ao item inicial, em parceira com instituições educacionais de ensino profissionalizante e técnico, tem-se desenvolvido atividades de formação profissional de mão de obra para o mercado de trabalho. Outro parceiro institucional que tem contribuído com as atividades de formação e capacitação profissional é o conselho da comunidade ${ }^{6}$, que proporcionou no ano de 2018 um curso de confeitaria, cujo público-alvo assistido pelo projeto foi composto por aqueles que possuíam aptidões para trabalhar no ambiente culinário.

Nesse momento, o Pedagogo tem o papel para além de organizador dos momentos educacionais, ele possui subsídios para desenvolver e estabelecer critérios que irão avaliar os membros mais capacitados para participar do projeto e, ao fim, avaliar os resultados. Todas essas atividades visam proporcionar a reinserção de um público-alvo ao tão competitivo mercado de trabalho.

A seguir, temos a compreensão de que o departamento pedagógico presente nesse Patronato precisa contribuir para o estabelecimento de padrões que devem ser

${ }^{6} \mathrm{O}$ artigo 80 da Lei de Execução Penal dispõe que haverá, em cada Comarca, um Conselho da Comunidade, composto, no mínimo, por um representante de associação comercial ou industrial; um advogado; e um assistente social; Na falta da representação prevista neste artigo, ficará a critério do juiz da execução a escolha dos integrantes do Conselho. Art. 81. Incumbe ao Conselho da Comunidade: I - visitar, pelo menos mensalmente, os estabelecimentos penais existentes na Comarca; II - entrevistar presos; III - apresentar relatórios mensais ao juiz da execução e ao Conselho Penitenciário; IV- diligenciar a obtenção de recursos materiais e humanos para melhor assistência ao preso ou internado, em harmonia com a direção do estabelecimento. 
adotados pelas demais áreas, sendo elas: Jurídica, Psicológica e de Assistência Social, no que diz respeito aos procedimentos adotados.

Ademais, como exposto, cabe ao departamento pedagógico, portanto, ao Pedagogo, elaborar diretrizes que visem desencadear um processo de avaliação institucional com a coordenação do Projeto e a direção do Patronato Penitenciário de Cascavel. Desse modo, é papel do profissional da Educação articular com a equipe de trabalho perspectivas de avaliação institucionais. Para além das atividades relacionadas ao ambiente laboral, cabe ao Pedagogo estabelecer estratégias e metodologias de desenvolvimento e execução de pesquisas científicas relacionadas à realidade desse órgão de fiscalização de penas restritivas de liberdade. E por fim, porém, não menos importante, cabe ao Pedagogo estabelecer subsídios aos colegas no que cerne à produção escrita e desenvolvimento prático de projetos de intervenção pedagógica.

Para melhor exemplificar sobre a importância do papel do Pedagogo em contexto não escolar, especificamente no contexto penitenciário, vale apresentar os subprojetos que são desenvolvidos na ambiência do Projeto Patronato. Entre os subprojetos que estão sendo desenvolvidos, podemos destacar o projeto transitar e o Projeto Força de vontade, ambos desenvolvidos pela equipe multidisciplinar do Patronato. O primeiro tem perfil de ressocialização e acompanhamento dos egressos que estão relacionados nos crimes de trânsito, abordando a temática de modo a estabelecer parâmetros educativos. O seguinte tem como público-alvo os assistidos que se enquadram no artigo 33 da lei de drogas, ou seja, tráfico de drogas. A perspectiva desse projeto visa proporcionar uma reflexão acerca das consequências sociais proporcionadas pelo uso e tráfico de drogas. Ademais, cabe ao Pedagogo proporcionar, no âmbito das metodologias de trabalho e organização do espaço pedagógico, subsídios para que a equipe multidisciplinar desenvolva tais medidas educativas e de ressocialização. 


\section{CONSIDERAÇÕES FINAIS}

Diante do exposto, visualizamos um outro perfil de Profissional da Educação:

o Pedagogo fora do Ambiente Escolar. Esse profissional, que, por vezes, em uma visão reducionista da profissão, é relegado apenas à função de professor dos anos iniciais, sendo desconsiderada a possibilidade de atuar em outras realidades. Vislumbrar tais atividades tão complexas, e relacionadas aos campos do direito, social e psicológico, ao trabalhar em uma equipe multidisciplinar, o Pedagogo é exposto à outra realidade e realiza atividades pouco conhecidas pelo senso comum. Ainda na academia, no curso de pedagogia pouco se é explorado, porém projetos de extensão como esse estão proporcionando atividades pautadas na formação desse profissional que é tão ampla.

Para exemplificar o trabalho interdisciplinar desenvolvido com os assistidos, visando a reinserção no mercado de trabalho considerando o entendimento de que a Lei de Execuções Penais valoriza o Trabalho como atividade norteadora do processo de ressocialização. Não reduzindo a ressocialização apenas à condição de ter um trabalho, mas também proporcionando condições mínimas para a manutenção da vida em sociedade.

Traremos para o diálogo os relatórios do Patronato para o mês de outubro de 2018. Sendo que, dos 1427 assistidos, cumprindo o Regime Semiaberto Harmonizado; Regime Aberto e Liberdade Condicional: 327 estão trabalhando em regime de Carteira Assinada, todos comprovados mediante apresentação de comprovantes (Holerite); 675 desenvolvem atividade laboral de forma autônoma, 178 encontram-se em situação de desemprego e outros 247 não informaram atividade laboral, descumprindo sua medida punitiva. Nesse sentido, configura-se como parte do trabalho do Pedagogo o desenvolvimento de atividades visando proporcionar o acesso trabalho de carteira assinada para os assistidos.

No que diz respeito aos reingressos ao mercado de trabalho e que realizam trabalho autônomo, boa parte deles possuem uma atividade laboral de fato, mas temos que considerar que a grande maioria sobrevive de bicos e trabalhos temporários que são comprovados mediante entrega de declaração de trabalhador autônomo a fim de dar cumprimento em sua medida do mandado de fiscalização. É 
fatídico que, como exposto anteriormente, o mandado de fiscalização - que imprime as condições do regime do assistido - pode tanto manter o assistido na rua, como regredi-lo de regime. Desse modo, ao comprovar atividade laboral, por meio de declaração, o assistido está cumprindo com a medida imposta, mas isso não garante que ele esteja realmente sendo ressocializado. Nesse ponto, o Pedagogo presente no Patronato tem a função primordial de proporcionar condições mínimas para que o assistido alcance, de fato, a ressocialização.

A partir dos dados expostos, estabelecendo paramentos evolutivos da atividade do Pedagogo no Patronato, apresentaremos os avanços ocorridos no ano. No início do desenvolvimento das atividades desse ano, mais especificamente no mês de março, o patronato possuía em média: 1113 assistidos, desses 294 possuíam trabalho registrado, enquanto, 503 realizavam trabalho autônomo. Se formos relacionar os dados do início do ano com os do presente momento, observamos um crescimento populacional de $28 \%$. Vale ressaltar que, ainda que não exista nada registrado por meio de Lei, nem que as empresas devam contratar egressos do sistema prisional, ocorrem em uma grande resistência por meio de empresários, cabendo ao Pedagogo, junto a Diretoria do Patronato conscientizar acerca da seriedade e necessidade dos assistidos. Ainda com essas dificuldades, o crescimento de trabalhadores registrados chegou a $11 \%$, tanto quanto o número de trabalhadores autônomos, que chegou a $34 \%$.

Problematizar esses dados foi algo complexo, mas que pode servir de parâmetro para ser utilizado para identificar a importância do desenvolvimento do trabalho do Pedagogo no Patronato. O perfil do assistido pelo Patronato, seja de escolarização, ou até mesmo de interesse na própria ressocialização acarreta apenas em uma das dificuldades da reinserção dessa mão de obra, culminando em baixos índices de ressocialização segundo a própria Lei de Execuções Penais. Ademais, cabe registrar que, apenas inserir um profissional nesse ambiente, sem proporcionar mínimas condições de materiais e investimentos para proporcionar cursos de capacitação e profissionalização dos assistidos, pouco surtirá efeito. Medidas paliativas, como parcerias com a iniciativa privada são realizadas, mesmo assim, ainda é pouco para alcançar números mais expressivos. 


\section{REFERÊNCIAS}

BRASIL. Lei no 9.503, de 23 de setembro de 1997. Institui o Código de Trânsito Brasileiro. Diário Oficial da União. Brasília, DF, p. 21201, 24 set. 1997. Disponível em: https://bit.ly/1WZcdjX. Acesso em: 28 ago. 2019.

BRASIL. Lei no 9.605, de 12 de fevereiro de 2008. Dispõe sobre as sanções penais e administrativas derivadas de condutas e atividades lesivas ao meio ambiente, e dá outras providências. Diário Oficial da União. Brasília, DF, 13 fev. 1998. Disponível em: https://bit.ly/1La6hQT. Acesso em: 28 ago. 2019.

BRASIL. Lei no 11.343, de 23 de agosto de 2006. Institui o Sistema Nacional de Políticas Públicas sobre Drogas - SISNAD; prescreve medidas para prevenção do uso indevido, atenção e reinserção social de usuários e dependentes de drogas; estabelece normas para repressão à produção não autorizada e ao tráfico ilícito de drogas; define crimes e dá outras providências. Diário Oficial da União. Brasília, DF, p. 2, 24 ago. 2006. Disponível em: https://bit.ly/Mba2eR. Acesso em: 28 ago. 2019.

BRASIL. Lei no 7210, de 11 de julho de 1984. Institui a Lei de Execução Penal. Diário Oficial da União. Brasília, DF, p. 10227, 13 jul. 1984. Disponível em: https://bit.ly/1JelrCR. Acesso em: 28 ago. 2019.

BRASIL. Ministério da Educação. Conselho Nacional de Educação. Resolução no 2/2015. Brasília, DF: Ministério da Educação, 01 jul. 2015. Disponível em: https://bit.ly/2HHTkR7. Acesso em: 28 ago. 2019.

BAUMBACH, T. R. D.; GUERRA, D. Homem, sociedade e Estado: aproximações e distanciamentos teóricos entre Karl Marx e Émile Durkheim. In: BENVENHO, C. M.; DIAS, J. F. A.; MARIANI, J. L. G.; WELTER, N. K.; PEREIRA, S. O. (org.). A ética em prática no ambiente escolar. Toledo: Vivens, 2016. v. 1, p. 220-226.

CASCAVEL (MG). Decreto Municipal no 13.532. Cascavel, PR: órgão oficial do município, Cascavel, PR, edição 12.549, p. 1-3, 08 jul. 2017.

CASCAVEL (MG). Patronato Penitenciário de Cascavel: plano de ação da pedagogia. Cascavel, PR: órgão oficial do município, Cascavel, PR, 2018c.

DURKHEIM, E. Educação e sociologia. 12. ed. Tradução de Lourenço Filho. São Paulo: Melhoramentos, 1978.

G1. Raio X do sistema prisional em 2018. Disponível em: https://bit.ly/2LhMllp. Acesso em: 09 ago. 2018.

IBGE. Cidades: população. IBGE: Rio de Janeiro, 2017. Disponível em: https://bit.ly/2UaO1Bk. Acesso em: 28 ago. 2019. 
LAKATOS, E. M; MARCONI, M. A. Fundamentos de metodologia científica. 5. ed. São Paulo: Atlas, 2003.

MACHADO, J. E. A ressocialização do preso à luz da Lei de Execução Penal. Monografia (Graduação em Direito) - Universidade do vale do Itajaí, Biguaçu, SC, 2008. Disponível em: https://bit.ly/2AOrufw. Acesso em: 28 ago. 2019.

O PARANÁ. Cascavel tem 6 monitorados. Disponível em: https://bit.ly/2NAwBgi. Acesso em: 02 mai. 2018.

PARANÁ (Estado). Secretaria de Estado da Justiça e da Cidadania. Decreto 8839, de 24 de novembro de 2010. Cria na estrutura organizacional do DEPEN, unidade de execução programática da Secretaria de Estado da Justiça e da Cidadania - SEJU. Diário Oficial do Estado do Paraná. Poder Executivo, n. 8349, p. 3, 24 nov. 2010. Disponível em: https://bit.ly/342UuDb. Acesso em: 28 ago. 2019.

PARANÁ (Estado). Departamento Penitenciário. Decreto Estadual no 1276, de 31 de outubro de 1995. [Dispõe sobre o Estatuto Penitenciário do Estado do Paraná]. Diário Oficial do Estado do Paraná. Poder Executivo, 31 out. 1995. Disponível em: https://bit.ly/31CZTys. Acesso em: 28 ago. 2019.

PARANÁ (Estado). Secretaria da Segurança Pública e Administração Penitenciária. Departamento Penitenciário. Patronato Penitenciário do Paraná - PCTA. Curitiba: DEPEN, 2018a. Disponível em: https://bit.ly/2L4uwYx. Acesso em: 28 ago. 2019.

PARANÁ (Estado). Secretaria da Segurança Pública e Administração Penitenciária. Departamento Penitenciário. Colônia Penal Agrícola do Paraná - CPA. Curitiba: DEPEN, 2018b. Disponível em: https://bit.ly/30F5Jzm. Acesso em: 28 ago. 2019.

SIMÕES, K. G. O sistema carcerário feminino na cidade de Cascavel: um estudo histórico-etnográfico. In: ENCONTRO REGIONAL DE HISTÓRIA, 16., 2014, Rio de Janeiro. Anais [...]. Rio de Janeiro: ANPUH-RIO, 2014. Disponível em: https://bit.ly/2MljhGS. Acesso em: 28 ago. 2019.

UNIOESTE. Edital $\mathbf{n}^{\circ} \mathbf{0 1 / 2 0 1 8}$, de 29 de março de 2018. Dispõe sobre a abertura de processo seletivo de bolsistas para o Programa Patronato Cascavel Unioeste, para o período 2018. Cascavel, PR: Unioeste, 2018. Disponível em: https://bit.ly/2ZwNivB. Acesso em: 28 ago. 2019.

Agradecimentos: Coordenação de Aperfeiçoamento de Pessoal de Nível Superior (CAPES). 